\title{
Correction: reduction of oxidative cellular damage by overexpression of the thioredoxin TRX2 gene improves yield and quality of wine yeast dry active biomass
}

Rocío Gómez-Pastor ${ }^{1}$, Roberto Pérez-Torrado ${ }^{1 *}$, Elisa Cabiscol ${ }^{2}$, Joaquim Ros $^{2}$ and Emilia Matallana ${ }^{2,3}$
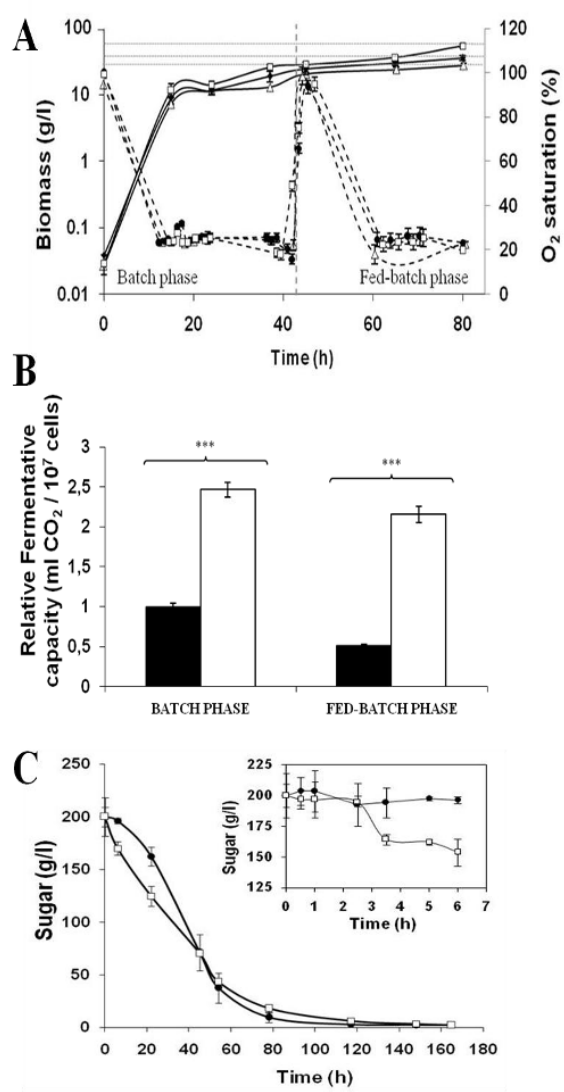

Figure 1 Improved performance of TTRX2 strain in biomass production process. (A) Biomass produced (continuous line) and oxygen saturation (discontinuous line) along bench-top trials of biomass propagation for T73 (black diamond), TTRX2 (white square) and TGSH1 (white triangle) strains by measuring $\mathrm{OD}_{600}$ from diluted

\footnotetext{
* Correspondence: rober@iata.csic.es

'Departamento de Biotecnología, Instituto de Agroquímica y Tecnología de Alimentos, CSIC, Apartado de Correos, 73 Burjassot (Valencia), E-46100, Spain Full list of author information is available at the end of the article
}

samples. Average of three independent experiments and standard deviations are shown. (B) Fermentative capacity of yeast biomass collected at the end of the batch and fed-batch stages of growth in bench-top trials of ADY production. Biomass from wild-type T73 (black bars) and TTRX2 (white bars) were dehydrated until 8\% moisture before performing the analysis. Data were normalized to the fermentative capacity of the batch sample from T73 strain. Average of three independent experiments and standard deviations are shown. Significantly different values compared to the control ( $p$ $<0.001$ ) were marked by asterisk. (C) Sugar consumption profiles during microvinification experiments using natural Bobal must for T73 (closed symbols) and TTRX2 (open symbols) strains. The start of

\section{Correction}

Following publication of this work [1] we have noticed a production error in the article. Figure 1 in the original version showed incorrect results, with graphs having been duplicated in error from another figure. The correct results for Figure 1 are shown below.

\footnotetext{
Author details

'Departamento de Biotecnología, Instituto de Agroquímica y Tecnología de Alimentos, CSIC, Apartado de Correos, 73 Burjassot (Valencia), E-46100, Spain. ${ }^{2}$ Departament de Ciències Mèdiques Bàsiques, IRBLleida, Universitat de Lleida, Spain. ${ }^{3}$ Departamento de Bioquímica y Biología Molecular, Universitat de València, Valencia, Spain.
}

Received: 17 February 2012 Accepted: 5 March 2012

Published: 5 March 2012

\section{Reference}

1. Gómez-Pastor Rocío, Pérez-Torrado Roberto, Cabiscol Elisa, Ros Joaquim Matallana Emilia: Reduction of oxidative cellular damage by overexpression of the thioredoxin TRX2 gene improves yield and quality of wine yeast dry active biomass. Microbial Cell Factories 2010, 9:9.

(c) 2012 Gómez-Pastor et al; licensee BioMed Central Ltd. This is an Open Access article distributed under the terms of the Creative B.T ed Central Commons Attribution License (http://creativecommons.org/licenses/by/2.0), which permits unrestricted use, distribution, and reproduction in any medium, provided the original work is properly cited. 
doi:10.1186/1475-2859-11-31

Cite this article as: Gómez-Pastor et al:: Correction: reduction of

oxidative cellular damage by overexpression of the thioredoxin TRX2

gene improves yield and quality of wine yeast dry active biomass.

Microbial Cell Factories 2012 11:31. 